\title{
Notas SObRe O CONCEITO de TRAdição em T. S. Eliot (À LUZ DOS ESCRITOS FILOSÓFICOS INICIAIS DO AUTOR)
}

\author{
NOtES ON THE CONCEPT OF TRADITION IN T. S. ELIOT \\ (IN THE LIGHT OF THE AUTHOR'S EARLY PHILOSOPHICAL WRITINGS)
}

André Cechinel

Universidade do Extremo Sul Catarinense

Criciúma-SC

\section{Resumo}

O presente artigo propóe-se a revisitar o conceito de tradição em T. S. Eliot à luz dos escritos filosóficos iniciais do autor, muitos dos quais publicados na íntegra pela primeira vez em 2014. Para tanto, o texto divide-se em três etapas fundamentais, voltando-se para a produção filosófica de Eliot, para a sua tese de doutoramento e para o clássico "Tradição e talento individual", este último projetado contra a leitura de sua obra ensaística inicial. O que se espera mostrar, em linhas gerais, é que tradição, para o autor, constitui um corpo orgânico e provisório de obras capaz de negar-se a si mesmo e de reconstituir-se a todo instante.

Palavras-chave: Eliot, tradição, modernismo, negatividade.

\begin{abstract}
This article intends to revisit the concept of tradition in T. S. Eliot in the light of the author's early philosophical writings, many of which were published for the first time in 2014. For this purpose, the text is divided into three fundamental parts, investigating the philosophical writings of Eliot, his doctoral thesis, and his essay "Tradition and the Individual Talent", the latter in the light of his initial production. In general, the purpose is to show that, for Eliot, tradition constitutes an organic and provisional body of works, capable of repeatedly denying and reconstituting itself.
\end{abstract}

Keywords: Eliot, tradition, modernism, negativity.

\section{Resumen}

Este artículo se propone a examinar el concepto de tradición en T. S Eliot, a la luz de los escritos filosóficos del autor, muchos de los cuales se publicaron en su totalidad por primera vez en 2014. Por lo tanto, el texto se divide en tres etapas principales, investigando los escritos filosóficos de Eliot, la tesis doctoral del autor y el ensayo "La tradición y el talento individual", este último a la luz de su producción inicial ensayística. Lo que se espera defender, en general, es que la tradición, para el autor, es un cuerpo orgánico y provisional de obras, capaz de negarse a sí mismo y de reconstituirse todo el tiempo.

Palabras claves: Eliot, tradición, modernismo, negatividad. 
Lido contra o pano de fundo dos escritos posteriores do autor e de sua apropriação inicial por parte dos new critics, o ensaio "Tradição e talento individual" (1919), de T. S. Eliot, já não se desvincula mais daquelas mesmas imagens a partir das quais encerramos hoje a própria poética eliotiana no centro do chamado "alto modernismo": "classicista na literatura, monarquista na política e anglo-católico na religião” (ELIOT, 1929: vii). E assim, o apelo que o texto faz à ideia de tradição seria indício tanto da austeridade do ensaísta quanto de um projeto literário conservador, centrado no estabelecimento de um cânone eurocêntrico que funcionaria como critério de avaliação definitivo para o "talento individual". Em suma, "Tradiçấo e talento individual" vê consolidado seu lugar como um ensaio "tradicionalista", esboçando um cânone estanque e alheio aos embates ideológicos que estruturam a presença de determinados nomes no cenário das genialidades que integram "a grande tradição", conforme título de um dos livros de F. R. Leavis.

É certo que a "nova crítica" contribuiu não apenas para fixar o argumento de Eliot justamente nesse lugar, como também para complementá-lo com afirmaçóes lacônicas cujo valor de verdade parece prescindir de verificaçáo, dado o seu caráter a princípio autoevidente: como prólogo para um livro que se ocupa da análise das contribuiçóes de apenas três poetas para o mundo moderno, Leavis assinala que "o leitor, sentindo a falta de alguns nomes, poderia reclamar que o critério de seleção é muito rigoroso. Essa foi justamente a intenção. De todo modo, nada de muito importante foi deixado de lado" (LEAVIS, 1960: 2). Em outras palavras, o cenário da poesia moderna, para Leavis, resume-se a três poetas: Eliot, Pound e Hopkins. Citar qualquer outro escritor seria abrir mão do rigor. Seja como for, o verdadeiro juiz que arbitra os julgamentos de Leavis, tal como ele mesmo adverte a todo momento, seria o próprio Eliot, como podemos notar nas avaliações que replicam as fórmulas primeiramente lançadas pelo autor da "terra desolada": "isso nos serve para lembrar a prevalência de certas limitaçóes no modo como o inglês tem sido usado na poesia desde Milton [...]. Milton utiliza apenas uma pequena parte dos recursos da língua inglesa" (LEAVIS, 1960: 82). A tese em pauta, como se sabe, é reprodução de alguns dos pareceres iniciais de Eliot sobre Milton: "No século XVII teve início uma dissociação da sensibilidade [dissociation of sensibility], da qual jamais nos recuperamos; e essa dissociação [...] viu-se agravada pela influência dos dois mais vigorosos poetas do século, Milton e Dryden" (ELIOT, 1989: 122).

Mas as fórmulas de Leavis constituem apenas um exemplo dos ditames conclusivos supostamente ancorados no ensaísmo de T. S. Eliot e, em particular, no ensaio "Tradiçáo e talento individual": "penso que muito pouco se produziu de boa poesia nos últimos anos, e que [...] o desejo de escrever versos de qualidade resulta, em quase todos os casos, de um motivo 
clínico: a tentativa de salvar a nossa própria sanidade" (EMPSON, 1961: ix); "julgar um poema é como julgar um pudim ou uma máquina. Exige-se que ele funcione” (WIMSATT; BEARDSLEY, 2002: 642). Esses pareceres acerca da literatura e da necessidade de uma avaliação que se limite a analisar a internalidade das obras, eliminando do horizonte da crítica elementos contextuais ou biográficos, não raro vêm acompanhados de citações dos ensaios de Eliot, como forma de conferir credibilidade às formulaçóes gerais em torno do funcionamento da maquinaria literária.

Difícil de conciliar com a tonalidade lacônica das avaliaçôes que alegam trabalhar a partir dos ensaios de Eliot, entretanto, são as formulaçóes mais abertas e menos taxativas do poeta, presentes, entre outros, no próprio "Tradição e talento individual": o escritor deve estar atento "para o óbvio fato de que em arte nunca se aperfeiçoa, mas de que o material da arte jamais é inteiramente o mesmo"; deve estar cônscio "de que essa mudança é um desenvolvimento que nada abandona en route, que não aposenta nem Shakespeare nem Homero, nem os desenhos rupestres do artista magdaleniano" (ELIOT, 1989: 41); ou ainda, "o objetivo do poeta não é descobrir novas emoçôes, mas utilizar as corriqueiras" (ELIOT, 1989: 47). Com efeito, conforme Sanford Schwartz (2009) observa, o conceito de tradição que Eliot elabora está sempre a serviço de um uso futuro, ou seja, Eliot pensa a tradição como um espaço de apropriação e transmutação posterior, e não como um objeto definido e situado num passado distante. A tradição, nesses termos, é algo que requer necessariamente a sua própria negação parcial ou reelaboração segunda para poder existir. Richard Poirier encerra a questão da seguinte forma:

Eliot sempre foi muito mais livre de dogmatismos sobre a literatura do que os seus seguidores [...]. “Tradição e Talento Individual”, seu ensaio mais famoso em virtude das asserçôes sobre o formato correto da tradição literária, é, na realidade, notável não pela ordem que propóe, mas sim pelas hierarquias que destrona, isto é, por recusar qualquer noção de passado ou literatura como algo fixo, qualquer ideia de que a ordem alcançada é mais que provisória" (POIRIER, 1992: 49).

Mas é a publicação dos ensaios filosóficos iniciais de Eliot (1905-1918), em 2014, juntamente com a leitura retrospectiva de sua tese de doutorado, lançada em livro pela primeira vez em 1964, que nos obrigam a revisitar o célebre ensaio "Tradição e talento individual" à luz de uma escrita negativa que projeta certas sombras sobre toda a luminosidade autocentrada que hoje paira sobre o poeta. Em outras palavras, os textos filosóficos de Eliot, muito mais próximos temporalmente de "Tradição e talento individual" do que o são vários de seus ensaios críticos posteriores, impossibilitam a recepção do poeta 
como tão somente um classicista ou conservador; o que vemos, antes, é um jovem escritor que luta para acreditar em algo, e que, nesse embate consigo mesmo, detona qualquer projeto filosófico, poético, político ou religioso que se queira como definitivo. O que Eliot arma, em seus escritos primeiros, é um mecanismo de rejeição ou mesmo destruição de todo e qualquer sistema, beirando um relativismo desesperador. Como o próprio ensaísta afirma, "os sistemas metafísicos estão condenados a subir como um foguete e a descer como um palito" (ELIOT, 2014a: 63). Fazê-los descer como "palitos" é a tarefa que o jovem filósofo reserva para si.

Nesse sentido, o presente ensaio propóe-se a defender o argumento de que a noção de tradição em Eliot, conforme desenvolvida no texto "Tradição e talento individual", está submetida a uma ideia de uso; trata-se, em poucas palavras, de um conceito fundamentalmente operacional, que traz em si o gérmen ou indício de sua própria negação. Para sustentar essa tese, o texto divide-se em três momentos principais: primeiramente, por meio de alguns dos escritos presentes no volume I da prosa completa de Eliot, publicado em 2014, busca-se apontar a desilusão do escritor em formação quanto aos sistemas filosóficos predominantes na universidade anglo-americana do final do século XIX e início do século XX; a seguir, a atenção volta-se para a tese de doutorado de Eliot, nunca defendida, intitulada Conhecimento e experiência na filosofia de F. H. Bradley, redigida em 1916 e publicada apenas em 1964, a fim de assinalar o ceticismo do autor quanto à possibilidade de consistência no que diz respeito ao conhecimento filosófico; por fim, o texto "Tradição e talento individual" é revisitado à luz dos escritos filosóficos em questão, com o intuito de indicar alguns pontos de contato entre o ensaio e as reflexóes anteriores do autor. A partir desse percurso argumentativo, "tradição" parecerá - é isso o que se espera aqui mostrar -, menos que um dado definitivo, tão somente um ponto de partida que, uma vez vislumbrado, torna-se desde já readaptado e corrompido.

\section{Os ensaios filosóficos de T. S. Eliot}

Para os leitores familiarizados com a imagem de Eliot consolidada pelos quase cem anos de sua recepção crítica, a primeira coisa que chama a atenção na leitura de seus ensaios filosóficos é o caminho negativo que o argumento do autor via de regra percorre; em outras palavras, são frequentes as discussóes que Eliot se diz incapaz de realizar ou compreender. Se, por um lado, a inconclusividade dos textos aproxima-se de uma espécie de cinismo autoesclarecido, é certo que, por outro lado, tal conduta é tão comum que é muito difícil avaliar o que de fato permanece de pé uma vez finalizado o argumento. Os exemplos de conclusóes inconclusivas nas linhas finais de seus 
ensaios são abundantes: "Todas as questôes éticas [...] dependem em última instância de uma entidade vaga conhecida como senso comum, fé ou resposta ao meio, mas certamente indeterminável” (ELIOT, 2014a: 55); “Então você afirma que a realidade é a experiência?’ Afirmo que sim, embora eu não saiba o que experiência significa" (ELIOT, 2014a: 64); "Mas sinto que divaguei demais num ensaio já demasiado vago e desconexo" (ELIOT, 2014a: 100); "O avanço do conhecimento, nesse campo, não se dá tanto ao acúmulo de novos fatos, mas à mudança das perguntas que fazemos a esses fatos"; por fim, "nada é contraditório até se converter num objeto, e tudo pode ser convertido em objeto, então tudo é contraditório" (ELIOT, 2014a: 185). Como dito, são infindáveis os exemplos, e em todos os casos eles nos passam a sensação de um filósofo em formação precocemente decepcionado com o alcance de sua atividade.

Conforme Manju Jain observa no livro T. S. Eliote a filosofia americana, os temas recorrentes da obra filosófica de Eliot incluem "a indeterminação do conhecimento, a contingência dos valores, a revisabilidade das teorias, o aspecto prático da linguagem, a relatividade das distinçōes" (JAIN, 1992: 80). A lista de Jain não nos deixa enganar: frente aos grandes sistemas filosóficos que notabilizaram os chamados "anos de ouro" da filosofia de Harvard no início do século XX, Eliot responde com uma máquina de destruição de teses. Pragmatismo, idealismo, materialismo, misticismo, neorrealismo - a Eliot interessa táo somente expor a parcialidade desses "-ismos" e das demais tentativas de sistematizar o conhecimento. Talvez seja justamente por isso que, percorrido o caminho argumentativo que mutila o objeto analisado e deixa muito pouco em seu lugar, resta ao poeta rejeitar qualquer encerramento conclusivo, escapando das armas "desconstrucionistas" que ele mesmo empunha em sua atividade analítica; para Eliot, no fim das contas, "o mundo é sempre mais real do que qualquer significado particular que atribuímos a ele” (ELIOT, 2014a: 161).

Um dos ensaios em que essa tendência negativa torna-se ainda mais evidente intitula-se "A interpretação do ritual primitivo" (1913-1914). Tratase do texto final apresentado a uma disciplina destinada a tecer um estudo comparativo de vários tipos de métodos científicos, ministrada pelo professor Josiah Royce. Entre os temas mais caros ao grupo estava, justamente, a questão dos chamados rituais "primitivos" e a possibilidade de uma metodologia científica capaz de descrevê-los apropriadamente. O ensaio final de Eliot, tal como Harry T. Costello observa em suas anotaçóes, busca discutir o campo da religião comparada "e até que ponto suas teorias situam-se no âmbito da descrição ou da interpretaçáo" (In: SMITH, 1963: 77). Conforme o ensaísta questiona em seu texto, "em que termos é possível haver uma ciência da religiáo?”. Eis o tema que Eliot se propóe a examinar. 
Ora, independentemente dos termos utilizados para empreender a análise, o que vale aqui ressaltar é a desilusão de Eliot quanto à tarefa que ele próprio atribui à ciência: frente ao desafio de descrever seus objetos, a investigaçáo científica parece desde sempre condenada a promover táo somente um encontro consigo mesma, sem jamais abandonar o campo da interpretação. Em outras palavras, a impossibilidade de permanecer por tempo suficiente no âmbito da descrição significa, para o ensaísta, o fracasso maior da ciência e sua dissolução final: "o que parecia ser um fato para uma dada geração revela-se, do ponto de vista da geração seguinte, apenas uma interpretação rejeitada" (ELIOT, 2014a: 109). Dessa forma, em suas supostas descriçôes, a ciência desliza de interpretação em interpretação, revelando muito mais acerca de si mesma do que sobre os objetos investigados: "confesso não ter um método melhor a oferecer, mas estou convicto de que os métodos em questão não nos oferecem o que estamos procurando; [...] acabamos postulando a nossa própria atitude e interpretando os assim chamados fatos por meio dela. Como isso poderia ser chamado de ciência?” (ELIOT, 2014a: 115).

A bem da verdade, diante da parcialidade da ciência, o único mérito da tentativa de estudar os rituais "primitivos" corresponderia, com efeito, a um mérito negativo, ou seja, a uma entrada no objeto táo autoconsciente de seus limites que evitaria qualquer tentativa de explicá-lo. Nesse caso, a ciência se aproximaria de uma espécie de catálogo "neutralizado" dos itens que costumam constar dos rituais investigados, de modo a compor um dicionário mítico mínimo sem qualquer pretensão analítica ou explicativa; as teorias "positivas", por outro lado, ao reclamar para si a verdade, convertem-se em "interpretação, mitologia, e, desse modo, podem ser eventualmente superadas" (ELIOT, 2014a: 114). A conquista maior da ciência, em suma, reside em sua própria negação parcial: é quando os cientistas abandonam a intenção de explicar ou interpretar seus objetos que eles de fato alçam as suas pesquisas ao estatuto de contribuição permanente. Decorre disso o paradoxo em meio ao qual Eliot nos abandona, a saber, a sugestão de que a ciência só pode ocorrer ali onde ela mais recusa cumprir a tarefa intelectual de compreender seus objetos. Em 1926, revisitando os apontamentos do texto de 1913-1914, o poeta tece comentários reveladores sobre a sua percepção dos problemas que tocam o registro histórico e a ciência de modo geral:

Há alguns anos, [...] realizei a humilde tentativa de demonstrar que em vários casos nenhuma interpretação de um ritual poderia explicar a sua origem. Afinal, o significado de uma série de atos constitui, para os próprios participantes, uma interpretação; o mesmo ritual, tendo permanecido praticamente inalterado, pode assumir diferentes significados para diferentes geraçóes de participantes, ao passo que o ritual em si pode ter se originado antes mesmo de a ideia de "significado" ter tido qualquer sentido (ELIOT, 2014b: 771-772). 
Em outras palavras, em vez de nos aproximar dos objetos, a interpretação passa a ser aquilo que converte a ciência numa atividade fadada a falhar, fazendo-a retornar a si mesma em seu pretenso contato com o outro. Para Eliot, quanto maior o mergulho interpretativo no objeto, tanto maior o desvio operado em relação a ele e, portanto, maior o grau de falsificação da atividade analítica. Ora, projetando desde já essa conclusão contra o conceito de tradição desenvolvido mais tarde pelo autor, poderíamos concluir que a permanente atualidade dos "monumentos do passado" decorre do simples fato de que náo podemos conhecê-los em definitivo, pois sempre que buscamos apreendê-los, acabamos corrompendo a sua natureza e alterando o seu estado, o que nos conduz a um processo infinito de recepção do passado. Tradição seria, nesse esquema, aquilo que náo pode ser desnudado e que se submete perpetuamente à apropriaçáo do tempo presente, solicitando uma interpretação que, paradoxalmente, tâo logo oferecida, prova ser apenas parcialmente verdadeira. Seja como for, se os ensaios iniciais de Eliot revelam o ceticismo do jovem filósofo em relação à filosofia e à ciência - "o progresso da ciência é, até certo ponto, um avanço por meio de insatisfação progressiva” (ELIOT, 2014a: 123) -, é na tese de 1916 que o argumento do autor se converte de forma definitiva num mecanismo sistemático de destruição de teses.

\section{A tese de doutorado sobre F. H. Bradley}

No prefácio que redige para o lançamento da tese em forma de livro, em 1964, Eliot se confessa tanto incapaz de compreender o argumento em questão quanto de pensar segundo a terminologia ali utilizada. Sobre o que restaria do estudo de 1916 em seus escritos posteriores, o poeta enfatiza táo somente certa proximidade de estilo, "o quanto a sua escrita foi formada a partir de Bradley e como ela pouco mudou ao longo de todos esses anos" (ELIOT, 2014a: 240). Ora, mesmo se apenas no âmbito do estilo, a influência de Bradley não pode ser suavizada; nas palavras de Hugh Kenner, um dos traços mais marcantes dessa influência na sensibilidade do poeta "está no modo de desarme hesitante e fragmentário com que Eliot defende seus argumentos e expressa suas opinióes, duvidando que seja a melhor pessoa para empreender o trabalho, ou dedicando um volume inteiro a 'notas para a definição' de apenas uma palavra” (KENNER, 1962: 47). Curiosamente, nesse esquema, ao afirmar não compreender a tese de 1916, Eliot parece ainda atuar segundo a "tática do desarme" que, conforme Kenner ressalta, resulta das leituras da filosofia de Bradley e de obras que fabricam muito mais uma arma de combate do que uma ferramenta de análise ( $c f$. MENAND, 2007).

Em linhas gerais, as premissas básicas da tese de Eliot encontram-se formuladas já no primeiro capítulo, intitulado "Sobre o nosso conhecimento da 
experiência imediata”. Para Bradley, o conhecimento e a experiência atravessam três etapas fundamentais: o primeiro estágio é chamado de "experiência imediata" [immediate experience], e constitui um momento abstrato do processo, anterior a qualquer dualismo ou ponto de vista privado, subjetivo ou objetivo; a seguir, passado o instante inicial em que o conhecimento corresponde a uma totalidade orgânica e pré-consciente, vemo-nos num mundo dualista, dividido em sujeitos e objetos - trata-se, em poucas palavras, do mundo que a ciência busca compreender e que se lhe apresenta como o único disponível; por fim, o terceiro e último instante diz respeito a um estado ou ponto de vista "Absoluto" e ideal, que incluiria e conferiria coerência a todos os demais pontos de vista, reconciliando, pois, as diferenças e distinçóes.

Sobre a "experiência imediata" - "ponto de partida e objetivo maior do nosso conhecimento" (ELIOT, 2014a: 245) -, Eliot comenta que só podemos ter notícias dela por meio de inferências e abstrações, já que, como totalidade orgânica e anterior a quaisquer dualismos, a experiência, se de fato imediata, não se oferece como objeto sensível a um sujeito consciente. Nas palavras de Eliot, a experiência imediata assemelha-se "a uma confusão ou sentimento, a partir da qual sujeito e objeto emergem” (ELIOT, 2014a: 247). Ou seja, o conhecimento e a experiência se iniciam num todo absoluto e verdadeiro, que, no entanto, "constitui uma unidade atemporal que não se faz presente em nenhum lugar [anywhere] nem para pessoa alguma [anyone]" (ELIOT, 2014a: 256). Ora, o ponto de partida do conhecimento não pode ser vislumbrado senão negativamente, e Eliot, nesse momento, projeta a sua descrença contra o próprio idealismo de Bradley: "se alguém afirmar que a experiência imediata [...] é aniquilação e escuridão absoluta, estou cordialmente de acordo" (ELIOT, 2014a: 256). A experiência imediata mostra-se verdadeira porque é uma unidade pré-dualista, porém, como tal, uma vez percebida, desfaz-se de pronto e nos abandona como sujeitos do saber em meio a um mundo de objetos, um mundo de "escuridáo absoluta", nas palavras de Eliot.

Atravessada a "experiência imediata", chegamos àquele estágio do conhecimento que Eliot averigua, entre outros, no ensaio aqui já citado, "A interpretação do ritual primitivo". A rigor, como desdobramento do fim da "experiência imediata", a teoria do conhecimento "se vê forçada a apresentar o seu relato ou como a história da mente em seu meio, ou como a história do mundo tal como este se apresenta à mente" (ELIOT, 2014a: 249). O cálculo é evidente e aproxima-se de um relativismo desencantado: o conhecimento é algo anterior a relaçóes e, num mundo de sujeitos e objetos, a teoria do conhecimento revela-se num beco sem saída, forçada a deslizar de interpretação em interpretaçáo sem nunca conseguir permanecer no campo da mera descrição. Embora o pensamento, a ciência e a filosofia busquem superar o dualismo, trata-se de uma empresa fadada ao fracasso, pois seus 
procedimentos são relacionais e discursivos e, dessa forma, acorrentam-se a estruturas temporárias e instáveis. Os apontamentos finais de Eliot na conclusão da tese são claros nesse sentido: "quanto ao problema do conhecimento, podemos dizer que ele simplesmente náo existe. $\mathrm{O}$ conhecimento, em outras palavras, não é uma relação e não pode ser explicado por meio de uma análise" (ELIOT, 2014a: 368); ou ainda, "nenhuma teoria do conhecimento [...] pode se estabelecer sobre uma estrutura firme ao tentar definir o tipo de relação que o conhecimento constitui, pois o conhecimento não é uma relação" (ELIOT, 2014a: 370).

Se o idealismo de Bradley nos reserva certa esperança quanto ao fim da jornada do conhecimento, uma vez que no Absoluto nada se perde, Eliot parece pouco inclinado a conferir validade permanente a essa categoria: "todas as coisas, de um ponto de vista, são subjetivas; e todas as coisas, de outro ponto de vista, são objetivas; e não há ponto de vista absoluto a partir do qual se possa pronunciar uma decisão" (ELIOT, 2014a: 248). A rigor, a desconfiança de Eliot quanto ao Absoluto é tamanha, que ele sequer aprofunda esse conceito na tese, seu interesse recaindo muito mais sobre as etapas anteriores do processo, como ele mesmo indica na introdução: "a natureza última do Absoluto não está no escopo do presente artigo” (ELIOT, 2014a: 256). Conforme Louis Menand (2007: 48) esclarece, o conceito de Absoluto formulado por Bradley "oferece uma espécie de cola metafísica final [...], porém Eliot não se sentiu tentado a utilizá-lo, e foi nesse ponto que ele mais diferiu explicitamente do filósofo".

Em suma, a tese de Eliot sinaliza uma conduta negativa, acentuando a relatividade de todo conhecimento, inclusive daquele por ele mesmo formulado. Tal como indicado pelo jovem filósofo, o conhecimento percorre três etapas fundamentais: a primeira delas, a "experiência imediata", pode ser inferida, mas jamais tocada diretamente; a segunda etapa nos lança num mundo de sujeitos e objetos, em que o conhecimento se assemelha a um barco à deriva, substituindo equívocos por equívocos; por fim, a terceira e última etapa, o suposto conhecimento Absoluto formulado por Bradley, apresentase de modo tão especulativo e improvável aos olhos de Eliot, que o ensaísta sequer se mostra inclinado a debatê-lo. No fim, talvez um dos aspectos mais interessantes da tese de Eliot seja o fato de que ele "lança o ceticismo de Bradley contra o próprio filósofo, mostrando que o seu sistema, como no caso de todos os sistemas metafísicos, estrutura-se sobre um dogma” (JAIN, 1992: 206). Resta, então, a inevitável pergunta: redigido cerca de três anos depois do texto de 1916, o ensaio "Tradição e talento individual” seria, em última instância, a negação das conclusóes relativistas e céticas da tese em nome de um absolutismo literário a princípio irreconciliável com as posições anteriores do jovem filósofo? 
A primeira coisa que cabe assinalar a respeito de "Tradição e talento individual" é que seu ponto de partida decorre não de uma convicção profunda sobre a literatura, mas sim do mais absoluto desespero epistemológico. A circulação tardia dos manuscritos filosóficos, nesse caso, foi de suma importância para que o ensaio de 1919 pudesse ser recebido como sinônimo de conservadorismo literário, cumprindo o lugar que lhe foi reservado pela "nova crítica". De todo modo, como as linhas iniciais do texto não deixam dúvidas, o mundo pós-Primeira Guerra Mundial, para Eliot, parecia absolutamente despedaçado, sem uma epistemologia que lhe respondesse à altura, e são as suas incertezas em torno da ciência e da filosofia que o levam a formular algum ponto de partida viável, ainda que arbitrário, para organizar o pensamento em torno de um núcleo minimamente comum. No lugar dos maniqueísmos que dividem a experiência em visóes incompatíveis, Eliot sugere não um novo dualismo, "tradição" versus "talento individual", mas sim a fusão dos termos:

Um dos fatos capazes de vir à luz nesse processo é nossa tendência em insistir, quando elogiamos um poeta, sobre os aspectos de sua obra nos quais ele menos se assemelha a qualquer outro. [...] Ao contrário, se nos aproximarmos de um poeta sem esse preconceito, poderemos amiúde descobrir que não apenas o melhor mas também as passagens mais individuais de sua obra podem ser aquelas em que os poetas mortos, seus ancestrais, revelam mais vigorosamente sua imortalidade (ELIOT, 1989: 38).

Por um lado, lida de modo descontextualizado, a passagem citada pode assemelhar-se a uma defesa incondicional do cânone ou a um academicismo que anula as novas geraçóes em nome da releitura livresca de certa tradiçáo passada fetichizada pelo autor; por outro lado, projetada contra os escritos filosóficos de Eliot, a passagem poderia esboçar, antes, um convite ao diálogo, ou melhor, uma abertura à diferença a ser operada num todo orgânico maior, capaz de superar o relativismo que ele via nas epistemologias estudadas em sua formação filosófica. Dessa forma, se é verdade o fato de que Eliot é um grande defensor da tradição, "a natureza dessa defesa é geralmente interpretada equivocadamente. A sua devoção à tradiçãa e à convenção não é uma expressão de absolutismo cultural, mas virtualmente o seu oposto: uma expressão de ceticismo radical em relaçáo a qualquer perspectiva filosófica" (PERL, 1989: 63), o que nos obriga a revisitar as posiçóes totalizantes a ele atribuídas ou que ele se impôs a si mesmo retrospectivamente. Trata-se, ainda hoje, de uma tarefa bastante difícil, pois, como David Chinitz (2003: 16) comenta, "Eliot se mostrou extraordinariamente eficiente no papel que lhe foi destinado, e a última coisa que alguém vai desejar, por assim dizer, é um Eliot irrastreável, 
que bagunce em vez de confirmar as noçóes mais conhecidas de literatura, cultura e modernismo".

Um outro aspecto decisivo de "Tradição e talento individual" refere-se à determinada instrumentalidade do conhecimento, isto é, o modo como a ciência, mesmo em sua errância infinita, oferece uma perspectiva mais ou menos coletiva a partir da qual passa a ser possível administrar os vários tipos de objetos e os diferentes erros que deles decorrem. Conforme Eliot conclui nas linhas finais da tese, "o mundo da verificação prática não tem fronteiras definidas, e é tarefa da filosofia manter essas fronteiras abertas. Se insisti na natureza prática (pragmática?) da constituição e significado dos objetos, é porque estamos falando de uma metafísica prática" (ELIOT, 2014a: 381). Se, para o jovem filósofo, a ciência está condenada a falhar, nem todos os erros simplesmente se equivalem, e o grau de verdade que os desvios alcançam está diretamente relacionado à capacidade de agregar pontos de vista ao seu redor, o que nos coloca diante de uma instrumentalidade ou praticidade do conhecimento.

Nesse sentido, quando Eliot afirma que "nenhum poeta, nenhum artista, tem sua significação completa sozinho. Seu significado [...] constitui a apreciação de sua relação com os poetas e artistas mortos" (ELIOT, 1989: 39), podemos compreender a sua fala de duas maneiras fundamentais: por um lado, tratar-se-ia novamente de uma posição classicista, que fetichiza o conhecimento do passado em detrimento das contribuiçóes oriundas do "caos" moderno; por outro lado - e aqui alinhamos "Tradição e talento individual" aos escritos prévios do autor -, o diálogo entre os novos escritores e "os poetas e artistas mortos" caminharia no sentido de pensar a literatura a partir da ideia de "comunidade literária", uma comunidade sempre incompleta e provisória, porém tanto mais eficiente quanto maior a sua capacidade de convocar e reunir as diferenças. De resto, cabe ressaltar que a dimensão coletiva ou comunitária da atividade artístico-literária sempre constituiu um ponto caro ao autor da "terra desolada", como Richard Badenhausen comenta no livro T. S. Eliot e a arte da colaboração:

Um dos aspectos mais permanentes da crítica de Eliot diz respeito à presença de um vocabulário que a todo instante evoca, sugere ou depende da atividade colaborativa: [...] "amalgamar", "assimilar", "equilibrar", "coletivo", "colocação", "combinação", "compósito", "composto", "convergir", "cooperar", "duplicidade", "harmonizar", "misturar", "recíproco", "reconciliação", "sincretismo", "síntese" e "uniáo". A expressão favorita de Eliot para marcar esse processo é "fusáo", que aparece em pelo menos trinta ensaios (BADENHAUSEN, 2004: 9).

Além de assinalar a dimensão coletiva da escrita e da atividade artística, todo esse vocabulário evidencia a ideia de uso antes debatida, ou seja, para Eliot, 
o conhecimento do passado se oferece como matéria-prima para manipulação posterior, por isso a necessidade de agência e o teor instrumental vinculados pelo léxico em pauta. A tradição é algo fabricado e que serve a um uso futuro, uso este que, por sua vez, também efetuará uma mudança significativa não só no novo "objeto" produzido, mas na própria matéria-prima utilizada para a sua fabricação; resumidamente, a tradição traz em seu seio elementos para a sua própria negação. Como lemos em "Tradição e talento individual", "o que ocorre quando uma nova obra de arte aparece é, às vezes, o que ocorre simultaneamente com relação a todas as obras de arte que a precedem" (ELIOT, 1989: 39). O aparecimento de uma nova obra de arte, oriunda de um processo de diálogo e manipulação do passado, significa a alteração desse passado por meio da redistribuição dos lugares que as obras e os nomes a elas associados ocupam: "quem quer que haja aceito essa ideia de ordem [...] não julgará absurdo que o passado deva ser modificado pelo presente tanto quanto o presente esteja orientado pelo passado" (ELIOT, 1989: 39-40).

Com efeito, seria importante mencionar aqui pelo menos dois casos emblemáticos da forma como Eliot desnaturaliza o passado em seus textos literários e ensaísticos, expondo a adaptabilidade e a potência negativa da tradição. Como um primeiro exemplo, vale observar o procedimento alusivo a que o poeta recorre em vários dos seus poemas. Ora, é de conhecimento geral o fato de que Eliot cita em seus versos inúmeros outros escritores e artistas do passado; o que não costuma ser comentado, entretanto, é o funcionamento particular que ele confere a essa prática: seus versos em muitos casos adulteram o texto citado ou mesmo o contexto do qual a citaçáo foi extraída, projetando sobre os poemas uma leitura por vezes inversa daquela sugerida pelo material de origem, o que conduz a impasses interpretativos que não se resolvem com a simples identificação da fonte em questão ou com a leitura do "original". O caso das "Notas sobre The Waste Land" - notas supostamente explicativas que Eliot adicionou ao poema para indicar as suas principais referências - é esclarecedor nesse sentido: em vez de estabelecer uma relação elucidativa entre o poema e o texto citado, as notas mutilam de tal modo as referências que elas mesmas pedem interpretaçáo. Em resumo, as notas parodiam qualquer entendimento de passado e tradição como algo estável ou permanente.

Como um segundo exemplo dessa manipulação dos escritores do passado e de reversóes operadas no cânone, cabe lembrar o conhecido caso John Donne, em que Eliot, a partir de críticas dirigidas a Milton e Dryden por meio da noção de "dissociação da sensibilidade", posiciona Donne num momento decisivo da tradiçấo literária inglesa, ápice de uma experiência poética ao mesmo tempo intelectual e sensitiva que a seguir se desfez. Nas palavras de Eliot, "para Donne, o pensamento era uma experiência; ele modificou a sua sensibilidade. Quando a mente de um poeta está perfeitamente aparelhada para o seu trabalho, ela está constantemente combinando experiências díspares" 
(ELIOT, 1989: 120). Resulta da perda da capacidade associativa a fragmentação da experiência que Eliot identifica na poesia romântica, sendo a tarefa dos novos poetas "associar", "agregar", "assimilar" e cumprir o desafio de unir elementos díspares. Seja como for, conforme Leyla Perrone-Moisés (1998: 100) conclui, "John Donne e os outros chamados 'poetas metafísicos' ingleses ficaram quase totalmente esquecidos durante quatro séculos, até serem redescobertos e revalorizados pelos modernos", o que se deve fundamentalmente ao trabalho ativo de Eliot em relaçáo à reescrita do passado.

Logicamente, esses dois casos são apenas expressão parcial de um trabalho mais amplo de apropriação e distorção dos escritores do passado, uma espécie de dialética da identificação e desidentificação que atua sobre aquilo que Eliot chama de tradição literária. Trata-se de um jogo de aproximação e estranhamento que atravessa a produção do autor com um todo, matizado segundo determinadas fases do seu percurso intelectual e certamente mais agudo em seus escritos primeiros, mas que pode ser vislumbrado nos textos críticos, poemas, peças teatrais e mesmo no trabalho como editor do periódico The Criterion, de 1922 a 1939. Todos esses elementos conduzem a uma ideia de tradiçáo menos ordenada, autocentrada, hierarquizada e prescritiva do que aquela que costumamos ver vinculada ao seu nome, uma tradição que traz consigo uma força disruptiva que jamais pode ser de todo pacificada.

\section{Considerações finais}

Um dos pontos que mais chama a atenção nos escritos filosóficos de Eliot, e que ajuda a desconstruir a imagem do autor comumente veiculada pelos manuais de literatura, diz respeito à insistência na relatividade do conhecimento e no trabalho precário realizado pela ciência e pela filosofia. Como lemos em um dos ensaios redigidos sobre Kant, "o vício está simplesmente na criação de distinçóes absolutas ali onde as distinçóes são puramente relativas. [...] Nenhuma ciência é completamente científica" (ELIOT, 2014a: 55). Em outras palavras, para Eliot, no campo da ciência e da filosofia, o avanço dos estudos se dá muito mais pelo acúmulo de diferentes formas de errar do que por uma trajetória retilínea rumo à verdade última. Sendo assim, preso perpetuamente ao campo parcial da interpretação, o conhecimento se vê diante da tarefa de reunir o maior número possível de pontos de vista em torno de si, para que sua forma de errar náo constitua apenas o resultado individual de determinada mente em particular. Escapar do individualismo e do solipsismo é um dos desafios primeiros da ciência, ou, em termos mais familiares, o conhecimento se solidifica ali onde ele "amalgama", "assimila", "equilibra", "combina", "harmoniza", "mistura", "reconcilia", "sintetiza" e "une”. Chegamos aqui ao próprio vocabulário de "Tradição e talento individual". 
Ao contrário do que é costumeiramente difundido sobre a ideia de tradição em Eliot, não se pode dizer que os escritores do passado compóem um quadro estável de referências eternamente válidas para o tempo presente. Antes, para Eliot, tradição é precisamente o oposto disso: tradição corresponde à mudança. Nesse sentido, se o conceito traz consigo a ideia de fluxo e de transformação, isto é, se ele deixa espaço para um processo de desidentificação dos clássicos e de inserção de novas obras, então ele responde a duas questóes fundamentais dos escritos filosóficos do autor, a saber, tanto a impossibilidade de um saber último quanto a necessidade de agregar diferentes leituras no entorno desse corpo móvel e provisório. Em vez de um roteiro literário coerente ou fixo, Eliot confecciona um panorama do passado como "modo de usar".

Por fim, é importante vincular esse entendimento "negativo" de tradiçấo à preocupação de Eliot quanto àquilo que podemos chamar de comunidade literária. A ideia de tradição, por um lado, ao acentuar a impessoalidade, solicita que os novos escritores vinculem suas obras a algo que ultrapasse a mera presença de si no mercado dos estímulos literários, conferindo um compromisso comunitário à sua atividade; essa mesma noção de tradição, por outro lado, ao desconstruir-se como totalidade diante dos novos autores, abrindo-se à diferença e modificando a sua concepção, impede que o passado seja fetichizado como um corpo imóvel e definitivo sem qualquer vínculo orgânico com o tempo presente. A tradição confere, em suma, um sentido histórico e político à atividade literária, sem o qual, aí sim, a crítica e a própria literatura acabariam inevitavelmente condenadas "a subir como um foguete e a descer como um palito” (ELIOT, 2014a: 63).

\section{Referências bibliográficas}

BADENHAUSEN, Richard. T. S. Eliot and the Art of Collaboration. Cambridge: Cambridge University Press, 2004.

CHINITZ, David E. T. S. Eliot and the Cultural Divide. Chicago: The University of Chicago Press, 2003.

ELIOT, T. S. Ensaios. Tradução, introdução e notas de Ivan Junqueira. São Paulo: Art Editora, 1989.

. For Lancelot Andrewes: Essays on Style and Order. Garden City: Doubleday, Doran and Company, Inc., 1929.

. The Complete Prose of T. S. Eliot. Vol. 1 - Apprentice Years, 1905-1918. Edited by Jewel Spears Brooker and Ronald Schuchard. Baltimore; London: John Hopkins University Press; Faber and Faber, 2014a. 
. The Complete Prose of T. S. Eliot. Vol. 1I- The Perfect Critic, 1919-1926. Edited by Anthony Cuda and Ronald Schuchard. Baltimore; London: John Hopkins University Press; Faber and Faber, 2014b.

EMPSON, William. Seven Types of Ambiguity. Mitcham: Penguin Books, 1961.

JAIN, Manju. T. S. Eliot and American Philosophy. Cambridge: Cambridge University Press, 1992.

KENNER, Hugh (ed.). T. S. Eliot: A Collection of Critical Essays. New Jersey: Prentice Hall, Inc., 1962,

LEAVIS, F. R. New Bearings in English Poetry: a Study of the Contemporary Situation. Ann Arbor: The University of Michigan Press, 1960.

MENAND, Louis. Discovering Modernism: T. S. Eliot and His Context. 2. ed. New York: Oxford University Press, 2007.

PERL, Jeffrey M. Skepticism and Modern Enmity: Before and After Eliot. Baltimore: The John Hopkins University Press, 1989.

PERRONE-MOISÉS, Leyla. Altas literaturas. São Paulo: Companhia das Letras, 1998.

POIRIER, Richard. The Performing Self: Compositions and Decompositions in the Languages of Contemporary Life. New Brunswick: Rutgers University Press, 1992.

SMITH, Grover (ed.). Josiah Royce's Seminar, 1913-1914: as recorded in the notebooks of Harry T. Costello. New Jersey: Rutgers University Press, 1963.

SCHWARZ, Sanford. Eliot's Ghosts: Tradition and its Transformations. In: CHINITZ, David E. A Companion to T. S. Eliot. Chichester: Wiley-Blackwell, 2009.

WIMSATT, W. K.; BEARDSLEY, M. C. A falácia intencional. In: LIMA, Luiz Costa (Org.). Teoria da literatura em suas fontes. Rio de Janeiro: Civilização Brasileira, 2002. v. 2.

André Cechinel. Doutor em Teoria Literária pela Universidade Federal de Santa Catarina (UFSC). É professor do Programa de Pós-graduação em Educação da Universidade do Extremo Sul Catarinense (UNESC).

E-mail: andrecechinel@gmail.com

Recebido em: 12/01/2017 Aprovado em: 15/03/2017 